\title{
Scottish home prices: compatible with Euro membership?
}

\author{
William Miles*
}

\begin{abstract}
Although the Scottish electorate voted down independence in 2014, Brexit has led to renewed calls from Scottish political leaders for a second referendum. Scottish independence would likely lead to joining the European Union, and this would obligate Scotland to eventually join the euro common currency. If Scottish home prices were not highly cohesive with those in euro zone countries, the ECB's monetary policy could cause major disruptions for Scottish housing, and, by extension, the Scottish economy. As an example, if most euro-country home values were rising, but those in Scotland were falling, the ECB would likely run a tight monetary policy, which would be devastating to housing conditions in Scotland. We accordingly investigate the co-movement of house prices in Scotland with those in eight major euro zone countries, as well as co-movement between Scottish and UK home prices, using a variety of metrics. The use of methods that are primarily linear indicates that joining the euro may not result in a large loss of co-movement with other regional housing markets, compared to Scotland's current correlation with UK national home prices. However, the use of a measure that takes into account differences in the magnitude, and not just the phase of cycles yields results indicating Scotland exhibits very little co-movement with other euro housing markets. Indeed Scotland has co-movement metrics within the euro countries at levels similar to those of Spain and Ireland, which both suffered devastating booms and busts. Thus leaving sterling for the euro could be highly problematic.
\end{abstract}

JEL classifications: R31, E32, F45

Keywords: Housing supply and markets, Business fluctuations, Cycles, Macroeconomic issues of monetary unions

\section{Introduction}

Monetary policy is easier to implement, and housing cycles less volatile, when different regional housing markets in a monetary union exhibit a high degree of comovement in their fluctuations. In the UK, if home values in Wales are rising towards bubble levels while those of Scotland are contracting, the Bank of England's policy will not be optimal for both regions. The loose policy that could help Scottish prices recover would exacerbate price increases in Wales, leading to financial vulnerability and resource misallocation in the former. In contrast, the restrictive policy that would be best for Wales could send Scottish prices lower at the worst possible time for homeowners and their creditors.

While the BOE doesn't formally target home values, the housing market has relevance for policy through its impact on the business cycle of the real economy.

\footnotetext{
* Wichita State University, 1845 Fairmount, Wichita, KS 67260-0078, USA, E-mail: william.miles@,wichita.edu
} 
House prices can affect the real economy through wealth effects, as well as through an impact on credit availability and spending via the financial accelerator. The global financial crisis of 2007-09 was sparked by a downturn in United States housing (indeed, for the US, "Housing IS the business cycle", according to Leamer $(2007,2015))$. Due to housing's importance to the economy, and the division of the UK into thirteen different regions, there have been numerous studies of house price co-movement in the United Kingdom (see Ashworth and Parker (1997), Cook (2003), Meen (1999) and MacDonald and Taylor (1993) for just several of many examples). Some studies find Scotland has a relatively low level of co-movement with the rest of the UK (Drake (1995), Abbott and DeVita (2013)).

A possibility for Scotland is that of eventually joining the euro zone. There was a referendum in 2014 on Scottish independence, which was defeated. However, the passage of Brexit in 2016 and the December 2019 parliamentary elections in which the Prime Minister Boris Johnson won a large majority and promised to complete Brexit and leave the European Union were followed by calls from Nicola Sturgeon, leader of the Scottish National Party, for another referendum on independence. Thus Scottish independence, accompanied by an attempt to stay in the EU, is a continued possibility. Should Scotland obtain independence and join (or re-join, as it were) the EU, it would be obliged to eventually adopt the euro currency. All EU members are officially obliged to do so sooner or later, with exceptions made only for the UK and Denmark.

This brings up the issue of how Scottish house prices would co-move with other euro housing markets. Would Scottish house prices display a high level of cyclical synchronization with euro country house prices, which would help make Scotland part of an "optimal currency area" in the euro zone? In contrast, if Scottish house prices did not co-move much with those of other euro countries, the region could find monetary policy from the ECB, which would be formulated with little regard for Scotland's conditions, highly problematic.

We accordingly analyze how closely Scottish house prices co-move with those in other euro zone nations. First, we examine correlations between Scottish and euro country house prices over our whole sample, and then calculate rolling correlations to see how linear co-movement has evolved over time. We then calculate the same measures for Scottish home values and those of the UK for comparison. As correlation 
is a purely linear measure, we next apply metrics developed by Mink, Jacobs and DeHaan (2012), called synchronicity and similarity. The synchronicity measure indicates whether two variables are in the same, or a different cyclical phase. That is, are both in contraction or expansion, or is one growing while the other is contracting? The synchronicity measure does not account for differences in cyclical amplitudes, however. For instance, if one region is in a mild recession, but another is in a much more severe downturn, their cycles are different, although the synchronicity measure would suggest a high level of co-movement. Moreover, optimal policies for each region would be different; the first region would benefit from a mild monetary easing, while the second would be best off with much stronger counter-cyclical measures.

Accordingly, Mink, et al. (2012) have developed a second measure called similarity, which takes account of differences in the amplitude of cycles between regions. Two regions could be in the same cyclical phase, but if their cycles differ substantially in magnitudes, they will score low in terms of co-movement by the similarity metric.

To anticipate our results, we find that while Scottish home prices have a greater linear association with those of the UK than those of most large economies in the euro zone, the difference is not that large for some euro countries, such as Finland and France. Moreover, using the synchronicity measure, Scottish home values appear to comove just as much, overall, with their euro counterparts as they do with those of the UK, depending on the sample. All of this would suggest Scottish home prices would lose little, in terms of co-movement with other regions in a central bank jurisdiction, by leaving the UK and joining the euro.

However, when we employ the similarity measure, Scotland exhibits much greater divergence from the collection of euro economies than previous measures, which failed to take account of different amplitudes, indicated. Scotland is next-to-last among the nine regions, exhibiting more co-movement than only Spain, which of course had a well-known housing boom and bust episode, and even less than Ireland, which suffered similar difficulties. Overall, the results indicate that for the Scottish housing market, leaving the pound could entail substantial risk. 
This paper proceeds as follows. The next section describes the previous literature. The third details the data and methodology. The results are described in the fourth section, and the fifth concludes.

\section{Previous Literature}

There have been numerous studies on house price co-movement between different regions in the UK, and a smaller but substantial literature on such comovement in the euro zone. The UK consists of thirteen separate regions, one of which is Scotland, with house price indices for all compiled by the Nationwide Building Society. One part of the literature on UK regional house price co-movement has focused on what is termed the "ripple effect". The issue with the ripple effect is whether house price shocks in London or the South East of the UK create "ripples" in the home values of other regions (see MacDonald and Taylor (1993), Drake (1995), Ashworth and Parker (1997), Meen (1999) and Cook and Thomas (2003) for some examples).

Some papers examine other types of house price interaction, such as whether home values across the UK regions converge to a long-run level. Cook (2003) finds that the ratio of regional to national house price indices appears non-stationary when standard, linear unit root tests are employed, which would indicate a lack of convergence. However, when the MTAR unit root test, which allows for asymmetric adjustment, is used, several regions appear convergent. Holmes and Grimes (2008) find the first principle component of UK regional house prices is stationary, from which they infer convergence.

What several papers on the topic find is that Scottish house prices seem to have relatively little co-movement with the rest of the UK. Drake (1995), for instance employs the Kalman filter and finds Scotland, as well as the North region show little convergence with the rest of the UK. Abbott and DeVita (2013) study long-run convergence among UK regions with the pairwise approach, and find UK home prices do not appear to converge overall. The authors do find, however, evidence that there are several "convergence clubs", or subgroups of UK regional home prices which do exhibit convergence. Scotland is not a member of any such group.

Given its status as a cross-national currency union, house price co-movement in the euro zone has been the focus of several studies ("Co-movement in house prices 
across countries may be particularly relevant in the euro area, given a general trend with monetary union toward increasing linkages in trade and financial markets' (Van Steenkiste and Hiebert, 2011, p. 299)). Alvarez, Bulligan, Cabrero, Ferrara and Stahl (2010) examine house prices and output co-movement for France, Germany, Italy and Spain. Using filtering methods, the authors find that co-movement for output is much higher than that for house prices among the four countries. Ferrara and Koopman (2010) examine the housing markets of the same four countries using unobserved components models. Similar to Alvarez, et al. (2010), these authors find more evidence of business cycle, rather than housing cycle co-movement. Gupta, Andre and Gil-Alana (2015) examine whether house prices in eight euro countries (Belgium, Finland, France, Germany, Ireland, Italy, The Netherlands and Spain) exhibit convergent relationships. The authors find that Germany, the dominant economy of the currency union, moves not in concert, but often in the opposite direction of other countries.

Miles (2019) finds, contrary to Alvarez, et al. (2010) that the advent of the euro common currency had no positive, and by some measures a negative impact on house price co-movement. This finding could be important. Some have claimed that the act of joining a currency union increases the synchronization of output across member countries (Frankel and Rose, 1998); if so, the euro may also increase the cohesion of assets like house prices. If this is the case, then perhaps Scottish house prices would exhibit a high level of co-movement with those of other European housing markets upon adoption of the euro. The findings of Miles (2019), however, cast doubt on this hope, and thus if Scottish house prices exhibit low co-movement with other European housing markets in the available sample, it is unlikely the adoption of the euro would increase such synchronization.

\section{Data and Methodology}

Our data is quarterly house price indices spanning 1975:1-2019:2. For Scotland, home values are obtained from the Nationwide Building Society website (https://www.nationwide.co.uk/about/house-price-index/download-

data\#tab:Downloaddata). We then obtain home prices for eight euro zone countriesBelgium, Finland, France, Germany, Ireland, Italy, The Netherlands and Spain, to examine possible Scottish co-movement in the euro zone. These are the same eight 
nations examined in Gupta, et al. (2015). We also, for comparison, obtain the national home price index for the UK. These nine national home price indices are from the Mack and Martinez-Garcia database at the Dallas Federal Reserve Bank (https://www.dallasfed.org/institute/houseprice\#tab2). Data from Scotland and all of the nations are seasonally adjusted.

Since we are examining cyclical co-movement we will filter the data to remove stochastic trends. As has become standard practice, we will utilize the ChristianoFitgerald filter (see Mink, et al., p. 219-220 for a discussion of the CF method's advantages vis-à-vis other band pass filters). We will extract cycles of between two and eight quarters, with the remainder of the series being the trend. As in Mink, et al. we will divide a given region's housing price cycle by its corresponding trend to yield the gap, and then analyze co-movement among Scotland's and other regional house price gaps.

We will first perform very simple correlation analysis among Scotland's house price gaps and those of the eight euro countries, for a rough gauge of co-movement. For comparison, we will also calculate the correlation between Scotland's gaps and those of the national UK index. If the correlation between Scotland and the UK is higher than that between Scotland and the euro countries, this would indicate Scotland's housing market is more cohesive with that of the United Kingdom than its potential euro partners.

We will first calculate these correlations for the entire 1975:1-2019:2 data set. To see if the advent of the euro may have changed house price co-movement, we will split the sample into two periods. The first, 1975:1-1998:4, covers the years before the euro, while the second, 1999:1-2019:2 includes only the years of the euro's existence. Splitting the sample at a point when we know the euro was created obviously creates an endogenous break problem, so inference based on this type of analysis is clearly tentative. We therefore calculate twelve-quarter rolling correlations for the entire sample, and in the spirit of Mink, et al., regress each rolling correlation on a constant and trend, and test for an endogenous break in each bilateral correlation between Scotland and the euro countries (as well as with the UK for comparison) with the Andrews-Ploberger test, and see if the break dates correspond to the adoption of the euro. 
Next, we will follow Mink, et al. and calculate a measure called synchronicity between Scotland and the euro countries, as well as between Scotland and the UK. Synchronicity is calculated in the following manner:

$$
\varphi_{\text {ir }}(\mathrm{t})=\left(\mathrm{g}_{\mathrm{i}}(\mathrm{t}) \mathrm{g}_{\mathrm{r}}(\mathrm{t})\right) /\left(\left|\mathrm{g}_{\mathrm{i}}(\mathrm{t}) \mathrm{g}_{\mathrm{r}}(\mathrm{t})\right|\right)
$$

In equation (1), $g_{i}(t)$ is the housing gap for Scotland or one of the euro countries, while $g_{r}(t)$ is the gap of the reference region. For the reference region, a particular country, such as Germany, could be chosen; however, results could be sensitive to such a choice. We will thus follow Mink, et al. and use the median of the euro countries and Scotland as the reference. When we compute synchronicity for Scotland and The UK for comparison, we will in that case use the UK national index, as it will be the only country with which Scotland's co-movement is compared, in that exercise.

Synchronicity has a maximum value of positive one, which it obtains when both $g_{i}(t)$ and $g_{r}(t)$ have the same sign in a given quarter. In this case there is expansion (or contraction) in both Scottish and reference home values; both are in the same cyclical phase. The minimum value of synchronicity is minus one. This occurs in quarters during which Scotland and the reference are in opposite cyclical phases-one is growing while the other is contracting.

As noted, measures of correlation, or even of being in the same cyclical phase, can fail to capture important differences in the amplitude of cycles. Assume, for instance, that Scotland seceded and joined the EU and the euro. If Scottish house prices are in a severe downturn, while those of the euro zone overall are merely in a mild contraction, the response of the European Central Bank would likely be mildly loose monetary policy. Those with an interest in Scottish housing, however, would prefer a very loose policy and not the modestly expansionary actions that would be optimal for the entire euro zone.

We thus calculate a measure first developed by Mink, et al. called similarity. This metric accounts for differences both in the phase of the cycle and in amplitude. Between a given country and the reference, similarity is: 


$$
\gamma_{i t}(t)=1-\left(\left|g_{i}(t)-g_{r}(t)\right|\right) / \sum_{i=1}^{n}\left|g_{i}(t)\right| / \mathrm{n}
$$

This measure can take on a minimum value of $1-n$, and a maximum value of one. We will of course calculate similarity for two samples as before; one for Scotland and the euro nations, and the other for Scotland and the UK.

Finally, we will, as with the rolling unconditional correlations, regress the similarity measures on a constant and trend and test for endogenous breaks with the Andrews Ploberger method.

\section{Results}

Table 1 displays the correlations between the cyclical gaps in Scottish house prices, computed with the CF filter, and those of the eight euro countries, as well as between Scottish gaps and UK gaps, for the whole 1975:1-2019:2 sample. The last column in the table shows the $\mathrm{p}$-value from testing the hypothesis that the correlation is zero against a two-tailed alternative. As displayed, Scottish housing, whatever its idiosyncracies within the larger UK market relative to other UK regions, displays the largest linear association with the UK national index. At the same time, correlations with Finland and France are both positive and significant. However, the correlation with Germany, the largest euro economy, and one with a persistent, clear voice for tighter monetary policy on the ECB, is not significant. The correlations with Spain, Belgium and Italy are also insignificant. The correlations with The Netherlands and Ireland are insignificant as well, although notably for these two countries, both are negative.

As the euro may have changed the relationship between different housing markets, we split the sample into two, the pre-euro 1975:1-1998:4 and post-euro 1999:12019:2 quarters. We acknowledge that while some previous studies have also split the sample into pre- and post-euro periods, doing so runs afoul of the "endogenous break" problem (Hansen (1992)), and therefore inference can only be tentative. Table 2 indicates that in the pre-euro sample, Scottish house prices displayed a higher degree of association with those of Finland than with the UK (although the correlation with the UK house prices was only slightly smaller)! The correlation with France is, as it was for the full sample, positive and significant. However, correlation is once again not 
significant for Germany, the largest euro economy, nor for any other euro economy. The correlations for The Netherlands and Ireland are again negative but insignificant, and in this pre-euro sample the same is true for Italy.

Table 3 displays the results for the euro era. In these years, the correlation of Scottish home prices with the UK is higher than that of any country in this time sample, and indeed higher than for any country in any period. On possibility for this result could be that the euro common currency drew housing markets within the currency union closer together, and perhaps further from those outside the monetary union. This might leave open the possibility that if Scotland joined the euro, it may experience greater comovement with countries in the currency union. However, doubt is cast on this possibility when we see that Scotland's correlation with France is also higher in the euro years than before. The same is true for co-movement with Spain and Italy. Germany also has a slightly higher correlation with Scottish house prices under the euro than before, although in neither period is the correlation significant at the five or even ten percent level.

On the other hand, Scotland's correlation with Belgium and The Netherlands is lower under the euro than before, but is significant in neither case. Similarly, for Ireland the correlation is slightly "higher", or less negative under the euro than before, but never significant.

As splitting the sample can cause misleading inference, we turn to the rolling bilateral correlations between Scotland the eight euro countries as well as between Scotland and the UK, which are displayed in Figures 1 through 9. As described, these are twelve-quarter rolling correlations. When conducting the Andrews-Ploberger test, we fit each with a constant and a trend, as Mink, et al. did for their similarity measure. A significant trend can give a clearer insight into the evolution of co-movement relative to splitting the sample at a known date.

As shown in the figures, in all cases the values at the end of the sample are lower than those at the beginning, with the one exception being the correlation with Germany. But in Tables 1 through 3, the correlation with Germany was never significant.

In Table 4, the linear trend is positive for the rolling correlations between Scotland and all countries. The trend is only significant, however, for the correlations with Belgium, France, Ireland, The Netherlands and Spain. The positive trend is notably 
not significant for either Germany or the UK. For those correlations with significant trends, we show the results of the Andrews-Ploberger break tests. A break was significant for the correlation with Belgium at 1984:2, for France at 1993:1, for Ireland at 2002:4, for The Netherlands at 2007:4 and for Spain at 1993:2. There is no clear pattern to the breaks and little evidence the euro had much effect in any direction; the break closest to the launch of the common currency is for Ireland, but it is still nearly four years after the euro's creation.

Thus far, basic correlation analysis would indicate that while Scotland is most closely tied to the UK overall, co-movement with some euro nations such as Finland and France is still relatively high. And although co-movement with Germany is not significant, there are significant, positive trends with France and four other euro countries, while the trend with the UK is not significant. Thus one could infer that a switch for Scotland from sterling to the euro could mean only a relatively small loss in terms of co-movement of home values with fellow members of the currency union.

Next, we turn to the results on the synchronicity measure. The average values over the sample are shown in Table 5. As described in the previous section, we calculate synchronicity for Scotland vis-à-vis the eight euro countries by taking the median of these nine total regions as our references, in accordance with Mink, et al. (2012). We then calculate synchronicity between Scotland and the UK separately.

As displayed in the table, Scotland, in terms of this measure, does reasonably well as a prospective euro member. It ranks fourth out of nine regions in terms of synchronicity average. It notably has a slightly higher value than Germany. Upon computing the synchronicity for Scotland and the UK we obtain the exact same average numeric value of 0.314607 , that we did for the average synchronicity between Scotland and the other euro countries. Thus by the synchronicity metric, Scottish home values display just as much co-movement with the major markets of the euro zone as they do with those of the national "sterling zone".

However, correlation and synchronicity only yield information on the linear relationship among variables and how often they are in the same cyclical phase, and do not address differences in cyclical variability. We thus turn in Table 6 and Figure 10 to results on similarity. As shown, when we take differences in cyclical amplitude into account, results are very different for Scottish housing markets. Among the current (and 
in Scotland's case, potential) euro countries, while five of the nine have positive similarity, Scotland's housing markets display a negative value. Moreover, Scotland is ranked next-to-last; only Spain has a lower similarity value. Spain of course had a disastrous boom and bust in its housing, which led to a very severe recession (unemployment reached nearly twenty-seven percent in its aftermath). And Scotland's mean similarity value is lower than that of Ireland, which also has a negative value. Ireland also had a notorious housing boom and bust followed by a very harsh recession.

We do note in Table 6 that when we calculate similarity between Scotland and the UK, we also get a negative average value (-0.307424) and one that is only slightly higher than that obtained for the euro (Scottish similarity with the UK is displayed in Figure 11). This does fit with some previous papers which have found Scottish house price dynamics somewhat idiosyncratic compared with those in the rest of the UK (Drake (1995), Abbott and Devita (2013)). However, it is also important to note that distress in Scottish housing will likely carry greater weight with the Bank of England than with the ECB should Scotland secede and join the euro zone.

We next, in Table 7, report the results from fitting the two similarity measuresScotland/euro and Scotland/UK-with constants and trends and testing for breaks with the Andrews-Ploberger test. The trend for Scotland/euro similarity is negative and significant, indicating that housing cycles between Scotland and the euro countries are becoming less alike over time, while that between Scotland and the UK is insignificant. Thus Scottish housing markets, as found here and in other studies, may display a fair degree of idiosyncrasy vis-à-vis the rest of the UK, but it is a characteristic that has existed for decades and at least does not appear to be getting more pronounced. As Scottish/euro similarity has a significant negative trend, we test for an endogenous break, and find significant structural change at 1989:4. Whether this is related to the ERM-in which UK monetary policy was "made in Frankfurt"-cannot clearly be determined. In any event, Scotland's similarity with euro housing markets is quite low and continues to decline.

\section{Conclusion}

Deciding Scotland's future, whether as a sovereign state in the EU using the euro currency or as a continuing member of the UK will require analyzing numerous issues. 
These include a desire for political sovereignty as well as the relative commercial costs and benefits of membership in the UK or EU. Results here should not be taken to imply that Scotland is better off overall in the UK, as there are many other factors to consider.

However, our use of the similarity metrics clearly indicates that Scottish house price cycles are not well-aligned with those of most euro economies. Given that macroeconomic policy in the euro will likely be set with little regard for Scotland, a lack of co-movement with euro housing markets would be a factor suggesting at a minimum, caution before joining the EU. 


\section{References}

Ashworth J., Parker S. (1997), 'Modelling Regional House Prices in the UK', Scottish Journal of Political Economy, 44, 225-246.

Alvarez L. et al. (2010), 'Housing Cycles in the Major Euro Area Countries', Banco de Espana Occasional Paper, 1001.

Cook S. (2003) 'The Convergence of Regional House Prices in the UK', Urban Studies, 40, 107118.

Cook S., Thomas C. (2003), 'An Alternative Approach to Examining the Ripple Effect in UK House Prices', Applied Economics Letters, 10, 849-851.

Drake L. (1995), 'Testing for Convergence between UK Regional House Prices', Regional Studies, 4, 357-366.

Ferrara L., Koopman S. (2010), 'Common Business and Housing market Cycles in the Euro Area from a Multivariate Decomposition', Banque de France Working Paper, 275.

Frankel J., Rose A. (1998), 'The Endogeneity of the Optimum Currency Area Criteria', Economic Journal, 108, 1009-1025.

Gupta R., Andre C., Gil-Alana L. (2015), 'Comovement in Euro Area Housing Prices: A Fractional Cointegration Approach', Urban Studies, 52, 3123-3143.

Hansen B. (1992), 'Testing for Parameter Instability in Linear Models', Journal of Policy Modelling, 14, 517-533.

Holmes M., Grimes A. (2008), 'Is There Long-Run Convergence among Regional House Prices in the UK?', Urban Studies, 45, 1531-1544.

Leamer E. (2007), 'Housing IS the Business Cycle', NBER Working Paper, 13428.

Leamer E. (2015), 'Housing Really is the Business Cycle: What Survives the Lessons of 200809?', Journal of Money, Credit and Banking, 47, 43-50.

MacDonald R., Taylor M. (1993), 'Regional House Prices in Britain: Long-Run Relationships and Short-Run Dynamics', Scottish Journal of Political Economy, 40, 43-55.

Mack A., Martinez-Garcia E., Gross V. (2011), 'A Cross-Country Quarterly Database of Real House Prices: A Methodological Note', Federal Reserve Bank of Dallas Globalization and Monetary Policy Institute Working Paper, 99.

Meen G. (1999), 'Regional House Prices and The Ripple Effect: A New Interpretation', Scottish Journal of Political Economy, 14, 733-753.

Miles W. (2019), 'Has the Euro Sustainably Increased Home Price Co-Movement?', Journal of Regional Science, 59, 931-961.

Mink M., Jacobs J., de Haan J. (2012), 'Measuring Coherence of Output Gaps with an Application to the Euro Area', Oxford Economic Papers, 64, 217-236.

Van Steenkiste I., Hiebert P. (2011), 'Do House Price Developments Spill over across Euro Area Countries? Evidence from a Global VAR', Journal of Housing Economics, 20, 299-314. 


\section{Appendix: Tables and figures}

Table 1. Correlations Between Scottish and National Housing Gaps. Whole Sample 1975:1-2019:2

\begin{tabular}{|l|l|l|}
\hline Nation & Correlation & P-value \\
\hline UK & 0.320911 & 0.000013 \\
France & 0.27559 & 0.000197 \\
Finland & 0.254958 & 0.000594 \\
Germany & 0.095975 & 0.202546 \\
Spain & 0.028582 & 0.704922 \\
Belgium & 0.00724 & 0.92363 \\
Italy & 0.005064 & 0.946578 \\
Netherlands & -0.02143 & 0.776515 \\
Ireland & -0.08576 & 0.255047 \\
The p-values are those from testing for the significance of the correlation against a two-tailed alternative.
\end{tabular}

The p-values are those from testing for the significance of the correlation against a two-tailed alternative.

Table 2. Correlations Between Scottish and National Housing Gaps. Pre-Euro Sample 1975:1-1998:4

\begin{tabular}{|l|l|l|}
\hline Nation & Correlation & P-value \\
\hline Finland & 0.269681 & 0.000344 \\
UK & 0.233179 & 0.001988 \\
France & 0.212489 & 0.00487 \\
Germany & 0.099293 & 0.18878 \\
Belgium & 0.01689 & 0.823166 \\
Spain & 0.00368 & 0.961182 \\
Italy & -0.01178 & 0.87621 \\
Netherlands & -0.022 & 0.771006 \\
Ireland & -0.09408 & 0.213096
\end{tabular}

The p-values are those from testing for the significance of the correlation against a two-tailed alternative.

Table 3. Correlations Between Scottish and National Housing Gaps. Euro Sample 1999:1-2019:2

\begin{tabular}{|l|l|l|}
\hline Nation & Correlation & P-value \\
\hline UK & 0.497769 & $<0.00001$ \\
France & 0.397426 & $<0.00001$ \\
Finland & 0.232318 & 0.002169 \\
Spain & 0.219954 & 0.003693 \\
Italy & 0.166893 & 0.027475 \\
Germany & 0.121027 & 0.109728 \\
Belgium & -0.02234 & 0.767693 \\
Netherlands & -0.03362 & 0.656658 \\
Ireland & -0.07041 & 0.351885 \\
\hline
\end{tabular}

The p-values are those from testing for the significance of the correlation against a two-tailed alternative. 
Table 4. Trends and Breaks for Rolling Correlations

\begin{tabular}{|l|l|l|l|l|}
\hline Country & Trend Coefficient & Standard Error & P-Value & Break \\
\hline Belgium & 0.002428 & 0.000655 & 0.0003 & $1984: 2$ \\
Finland & 0.0000 & 0.000401 & 0.8145 & None \\
France & 0.001399 & 0.000496 & 0.0054 & $1993: 1$ \\
Germany & 0.000189 & 0.000539 & 0.7265 & None \\
Ireland & 0.001966 & 0.000522 & 0.0002 & $2002: 4$ \\
Italy & 0.0000 & 0.000625 & 0.9629 & None \\
Netherlands & 0.00142 & 0.000475 & 0.0032 & $2007: 4$ \\
Spain & 0.00347 & 0.000439 & 0.0000 & $1993: 2$ \\
UK & 0.000648 & 0.000396 & 0.1036 & None
\end{tabular}

These are the rolling correlations between Scottish house prices and those of each country listed. The data is from 1975:1 to 2019:2, and a twelve-quarter rolling correlation was calculated. Each rolling correlation was fitted with a constant and trend, and then tested for structural change with the Andrews-Ploberger endogenous break. test. The p-value indicates the significance of the trend. Significant breaks were found for the correlations with Belgium, France, Ireland, The Netherlands and Spain.

Table 5. Average Synchronicity Results

\begin{tabular}{|l|l|}
\hline Country & Synchronicity \\
\hline Italy & 0.47191 \\
France & 0.43820 \\
Spain & 0.35955 \\
Scotland & 0.31460 \\
Belgium & 0.30337 \\
Germany & 0.30337 \\
Neth. & 0.28089 \\
Finland & 0.269663 \\
Ireland & 0.258427
\end{tabular}

The average synchronicity values over the sample were calculated using the median gap among Belgium, Finland, France,

Germany, Ireland, Italy, The Netherlands, Spain and Scotland. We note that when synchronicity was calculated between

Scotland and the UK, the value was 0.314607-which is exactly the same as that found using euro countries. 
Table 6. Average Similarity Results

\begin{tabular}{l|l|}
\hline Country & Similarity \\
\hline Belgium & 0.69476 \\
Germany & 0.56625 \\
France & 0.48570 \\
Finland & 0.22665 \\
Italy & 0.16162 \\
Neth. & -0.1057 \\
Ireland & -0.2831 \\
Scotland & -0.3144 \\
Spain & -0.7700 \\
The average similarity values over the sample were calculated using the median gap among Belgium, Finland, France, \\
Germany, Ireland, Italy, The Netherlands, Spain and Scotland. We note that when similarity was calculated between \\
\multicolumn{2}{|l}{ Scotland and the UK, the value was -0.307424, which is slightly bigher than that found using euro countries. }
\end{tabular}

Table 7. Trends and Breaks for Similarity

\begin{tabular}{|l|l|l|l|l|}
\hline Similarity Measure & Trend Coefficient & Standard Error & P-Value & Break \\
\hline Scotland/Euro & -0.004928 & 0.001721 & 0.0047 & $1989: 4$ \\
\hline Scotland/UK & 0.000574 & 0.000969 & 0.5540 & None \\
\hline
\end{tabular}

Each similarity measure was regressed on a constant and trend, and tested for a break with the Andrews-Ploberger method. 
Figure 1

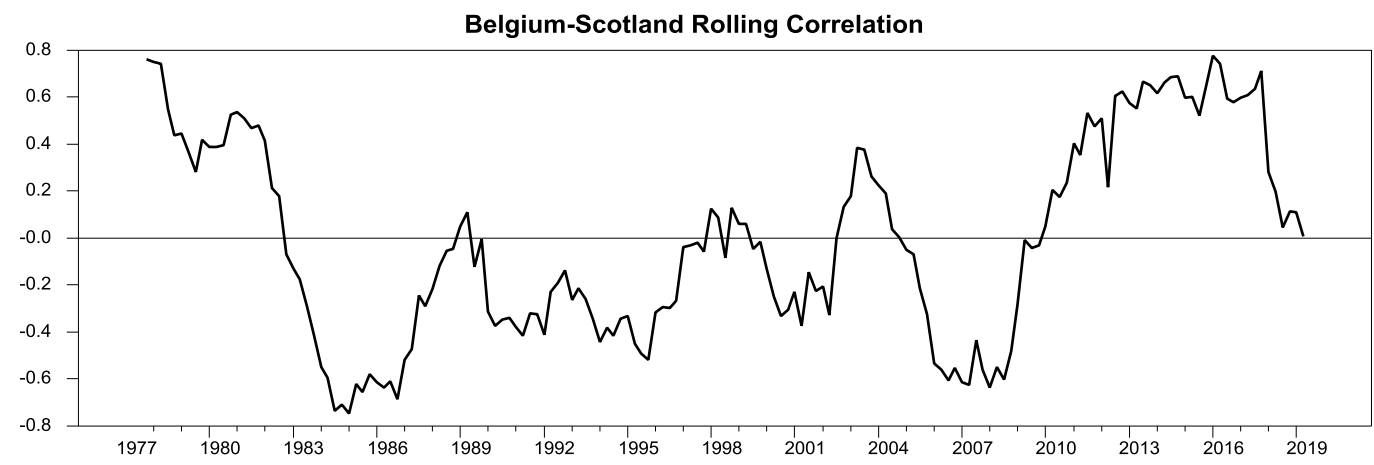

Figure 2

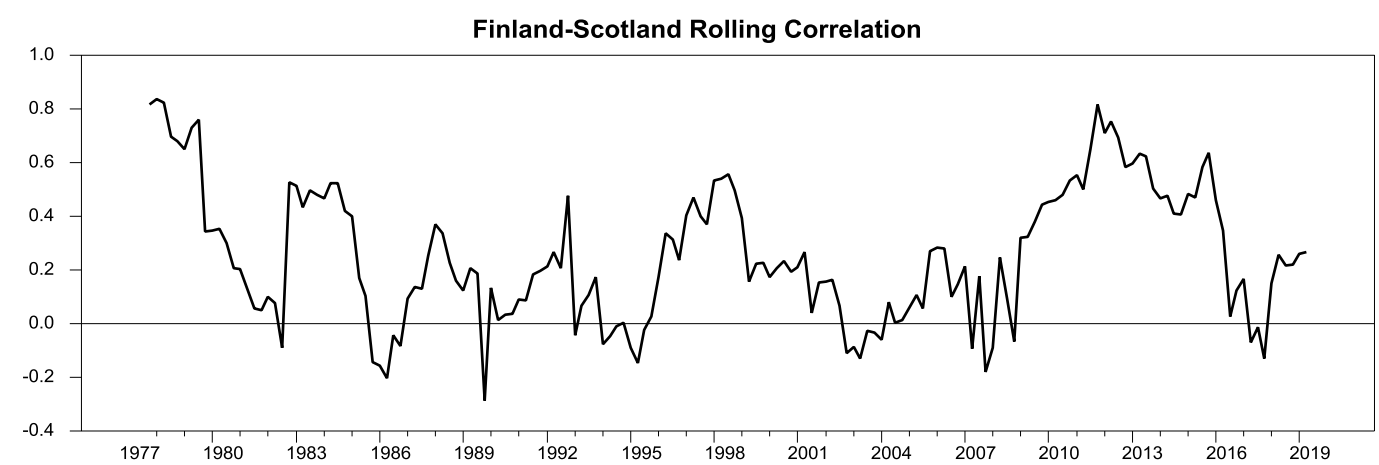

Figure 3

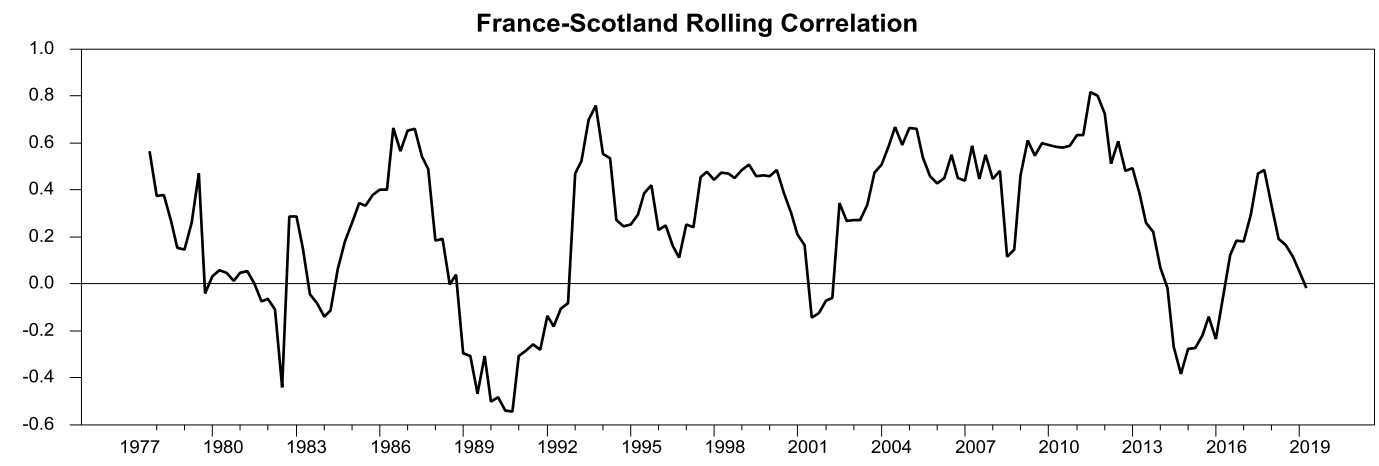


Figure 4

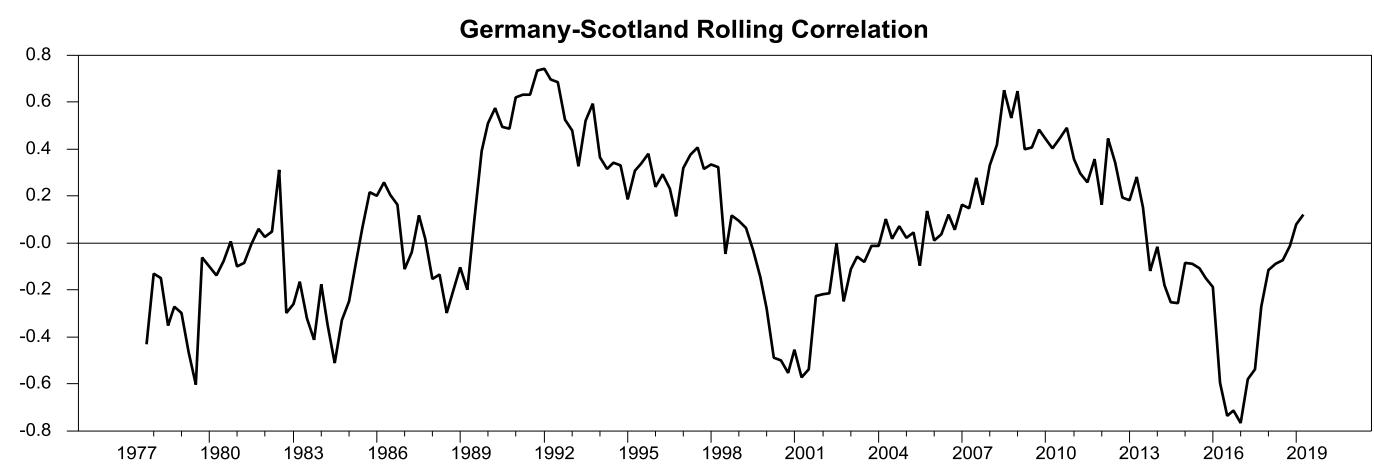

Figure 5

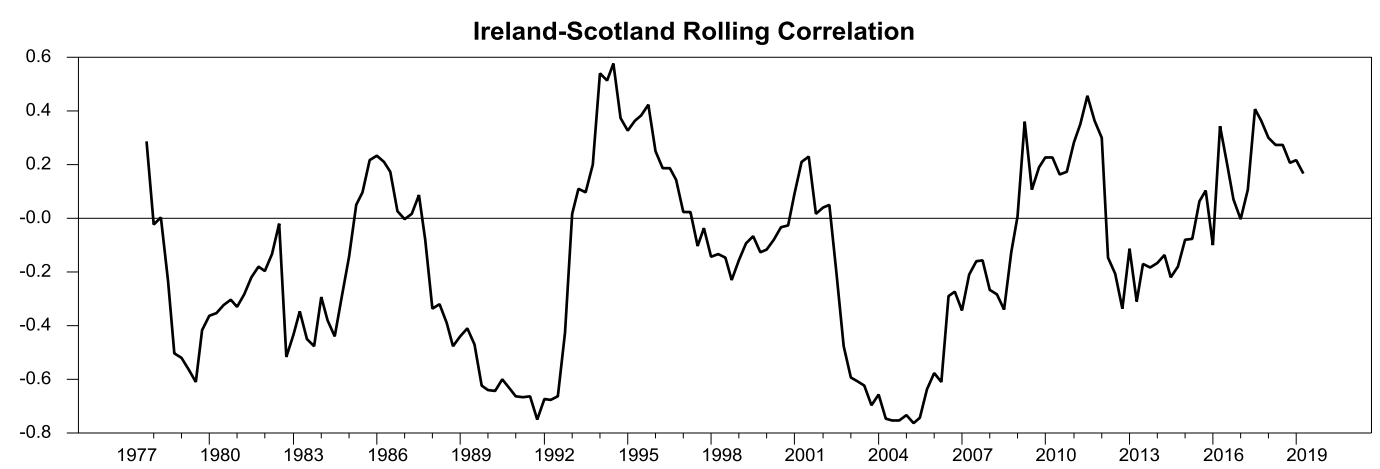

Figure 6

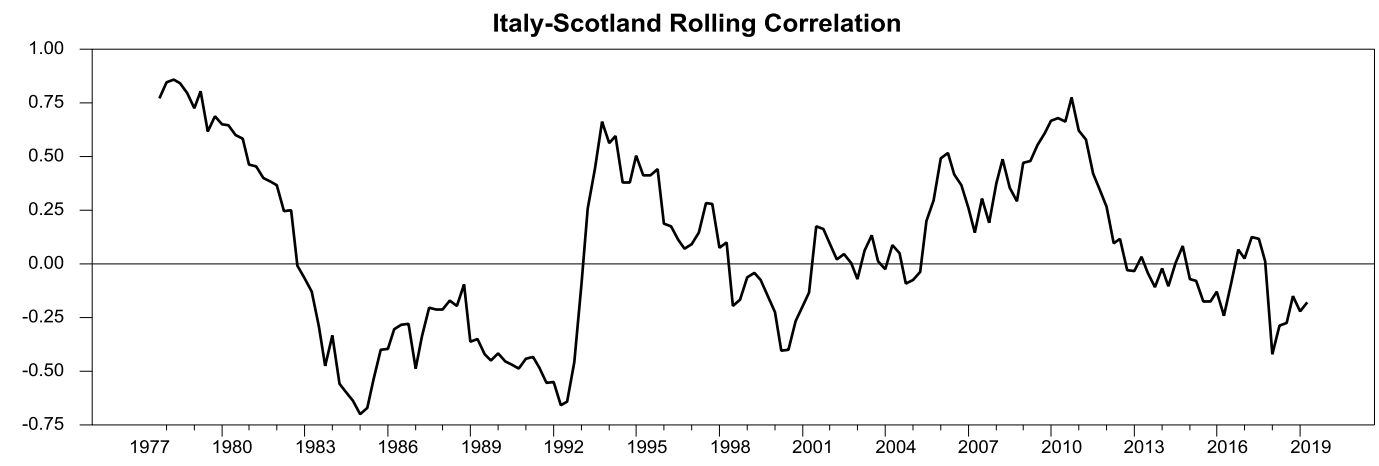


Figure 7

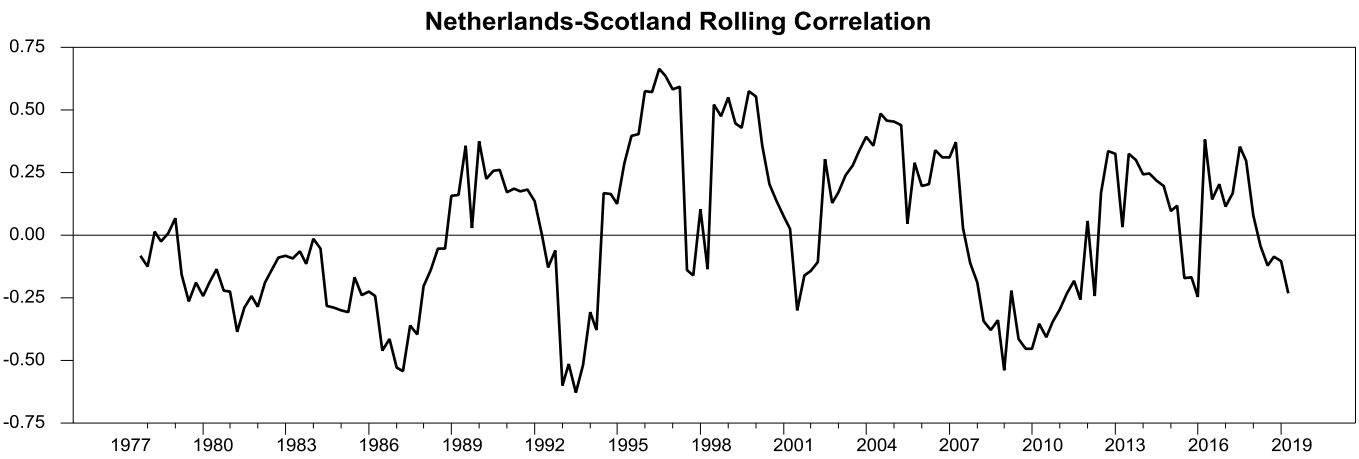

Figure 8

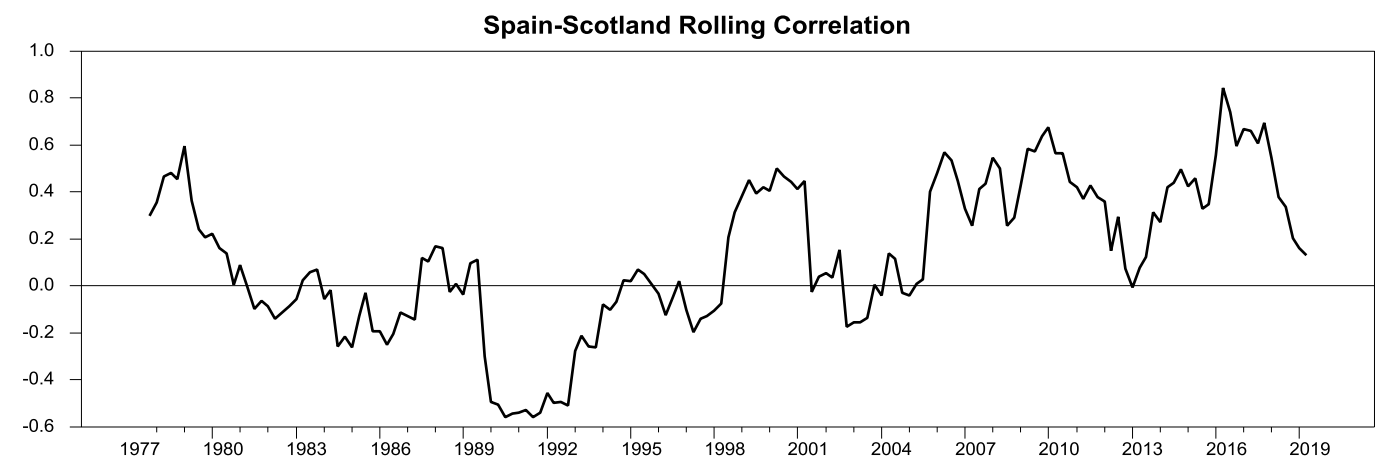

Figure 9

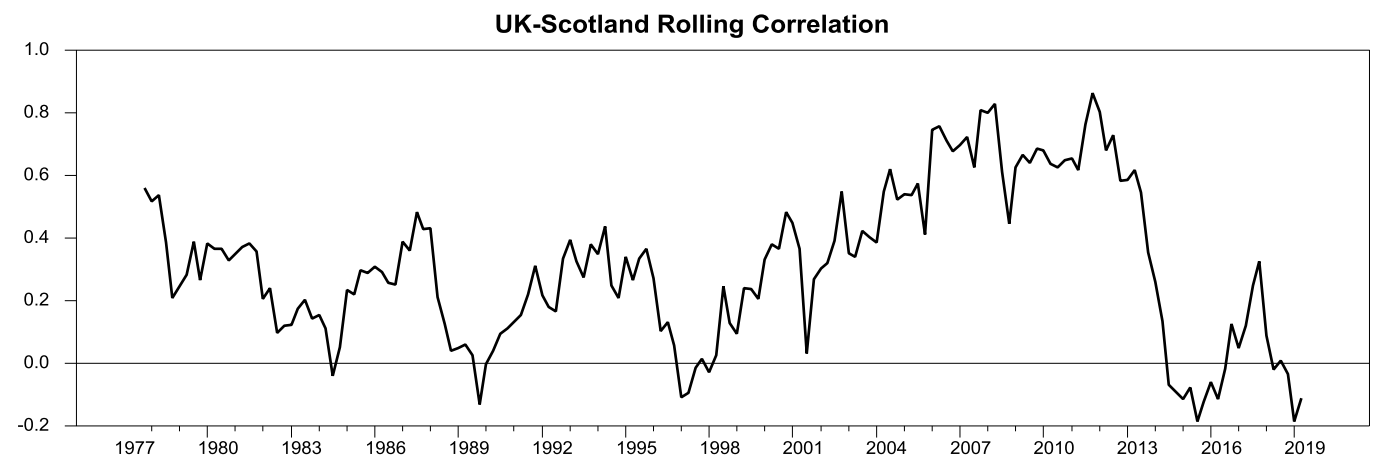


Figure 10

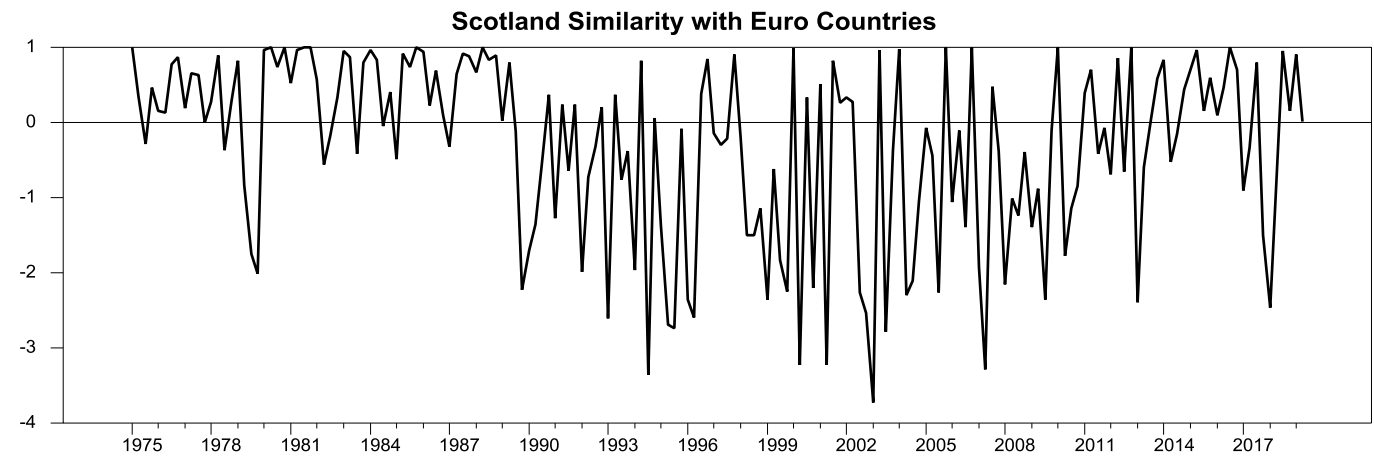

Figure 11

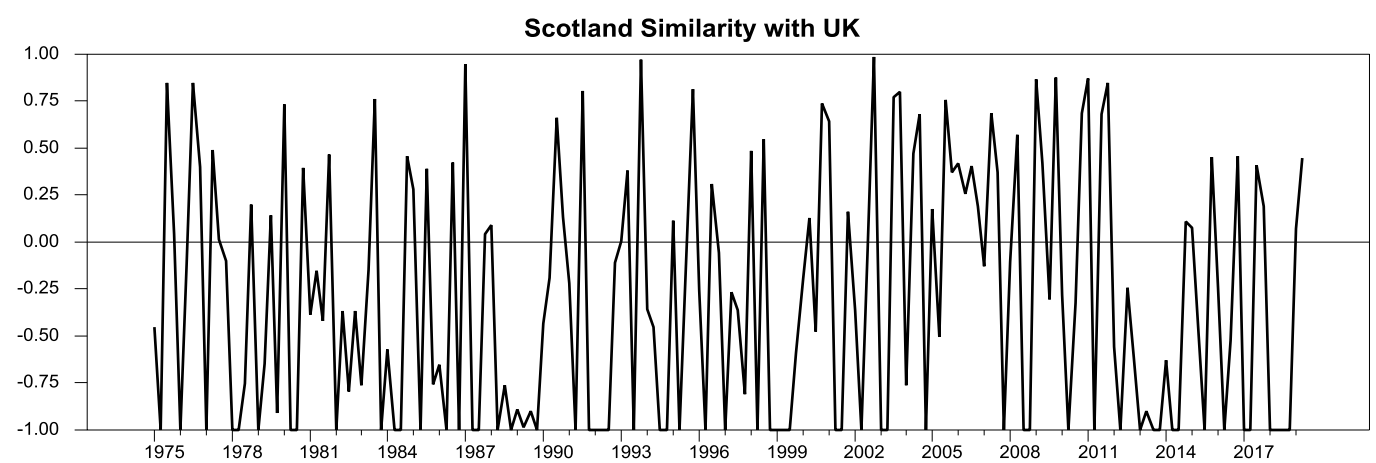

